\title{
Research on the Development of Existing Taoist Architecture Art in Qingcheng Mountain, Sichuan
}

\author{
Yan He ${ }^{a}$, Liang Yan ${ }^{b}$, Hongying Zhu ${ }^{c}$, Jixuan Bo ${ }^{d}$, Xuemei Zhange, and Can Cuif \\ School of Architecture and Urban and Rural Planning, Sichuan Agricultural University, Dujiangyan \\ 611830, China; \\ a1069335296@qq.com, ${ }^{b} 51027540 @ q q . c o m,{ }^{c} 583505331 @ q q . c o m,{ }^{d} 739511834 @ q q . c o m,{ }^{e} 264890$ \\ 7093@qq.com, ${ }^{f} 1365388421 @ q q . c o m$
}

Keywords: architectural decoration; Qingcheng Mountain, Sichuan; artistic expression

\begin{abstract}
As the only indigenous religion among the three major religions in China, Taoism has a significant influence on the natural outlook on life and the formation of a human being of Chinese. The decorating art of architect, as the tool of taoism-cuiture publicity and atmosphere illustrating, is continually developing in combination with civilian residence. From the relatively independent religious art to the decorative form that caters to the world's good wishes and fully enters into the world, the study on the decorative art of the Qingcheng Mountain Taoist Group, which plays an important role in the history of Taoism, is of great significance for understanding the folk architecture culture of China.
\end{abstract}

\section{The development history of Taoism and the significance of the study of the Qingcheng} Mountain Taoist Temple

The culture of Taoism is accompanied by the primitive society of ancient China to the end of feudalism. It is subtly influenced by the traditional culture and the customs of the people. It focuses on the teaching tenet of "Longevity, Essence and Immortality", pursuing the self-self and super-ego of life, exploring the "oneness of heaven and earth", and thinking "Heaven corresponding" way. In the long history, from the Confucianism, the Mohist, the military of the pre-Qin Dynasty to the theology and the Buddhism that was later introduced to China, Taoism has always been positively influenced and integrated by the classical doctrine. Confucius tried to improve social relations through "rites", thereby promoting social stability, and achieving the initial realization of "longevity ". The Confucian morality is also considered to be the core of Taoist ethics. Taoism's approval of Dayu is not only a kind of inheritance of Mohism's thought of "humility as the foundation, nourishment as the care", but also a kind of recognition and admiration of Dayu's achievements in water control, remarkable improvement of social productivity, the establishment of Xia Dynasty into the ancient civilized era; and the issue of military use is closely related to the peace and rest of society. Taoism has always advocated "governing the country by body and country", "managing the world and seeking peace". When Taoism became the carrier of Taoist culture, the thoughts of the military also 
became an important part of it. The history of the military family, such as Jiang Taigong and Zhang Liang, has also become a god of Taoism. With the change of the dynasty, the development of Taoism has gradually matured and has a far-reaching influence on the people. In the Sui and Tang Dynasties, the rulers further pushed Taoism to a higher and more important stage in order to stabilize the feudal regime. In addition, there are also foreign cultural factors that motivate Taoism to rise - Buddhist thought. When Buddhism came to Middle-earth, Taoism was in the process of revival. The basic purpose of Buddhism is to relieve the distress of life and death, and to achieve the "nirvana" realm of eternal happiness. The early Buddhist scriptures mainly used Taoist vocabulary, so people initially regarded Buddhism as a spiritual phenomenon such as Lao Zhuang Taoism. At the time of its thought establishment, Taoism also relied on Buddhism to have room for making up for it. ${ }^{[1]}$ This phenomenon of cultural doctrine blends better to promote the diversified development of Taoism. The use of Taoist art as a carrier to spread Taoist beliefs is an inevitable requirement of Taoist activities. It is also the crystallization of religious believers expressing their empathy and expressing their aesthetic tastes.

Qingcheng Mountain is one of the four famous sacred mountains in China, and one of the five celestial mountains. At the end of the Western Han Dynasty, Yin Changsheng, who was known as one of the "The eight immortals in the Sichuan", entered the Qingcheng Mountain to cultivate; in the early years of the Eastern Han Shun Emperor, the Tianshi Taoist leader Zhang Daolin went to Heming Mountain to practice the Taoist Temple. Heming Mountain and Qingcheng Mountain belong to the Gumin Mountain Range. After two years of writing the twenty-four books, Zhang Daoling came to Qingcheng Mountain from Heming Mountain to make a rumor, and preached a local religion in China. Feathered in the mountains. These laid the foundation for Qingcheng Mountain to become the head of the four famous mountains of China. The research on the Qingcheng Mountain Taoist group with profound representative significance of Taoism culture and exploring the cultural and artistic connotation of its architectural decoration is an indispensable step in understanding the traditional culture of China.

\section{Qingcheng Mountain Taoist Architecture Art Deco Section Headings Section Headings}

\subsection{Mountain door decoration}

The front door in Qingcheng Mountain is both the door to the mountain and the door to the view. The Jianfu Palace in front, the existing building was rebuilt during the Guangxu reign of the Qing Dynasty (AD 1888)."Qingcheng Mountain Record" has records: "The Yellow Emperor sealed it as Wuyuezhang, who is the top of the Yuelu, and respected the immortal." It shows that Jianfu Palace bears the role of the facade and leadership of Qingcheng Mountain and has an important position. Therefore, the roof decoration of the building, especially the entrance door, is more magnificent than its own size. The roof sculpture is symmetrical and compact. The top of the top, the color is yellow and green as main colors and the colors of the moss on the roof. Its shape is opposite to the double dragons, and together they jack up a brick red gourd. There is also a combination of amrta-kalasa and cauldron at the bottom. The overall shape is a common triangle in Taoist architecture. The moiré and the two sides of the scorpion kiss are connected to each other, and the position of the upper part of the ridge is basically filled, and the style is complex and colorful, which is remarkable.

Unlike many official buildings, the slanting ridge of Jianfu Palace does not have any fairy beasts as decoration, but simply lifts the wing angles. At the wing corner, the pattern is formed with gray model pottery and the leaves are attached to the surface that make the corner an important decorative part. The end of the vertical ridge is shaped like a fairy, which enriches the Taoist feeling of the 
building. At the same time, the complexity of the three-story roof is maintained. It doesn't seem to change abruptly. The ancient ruins of Jianfu Palace have been unearthed in the thin and long form of the gray pottery stalks of the lips of the Sanxingdui bronze statues, and the glazed ridges of green, brown and yellow. The combination of carving,statue,colors and glaze is the glazed piece of clay pottery. It can be seen that since the Song and Yuan Dynasties, there has not been much change in the decoration of the Fugong Palace.

Another mountain gate is also the "Chicheng Pavilion" of the mountain entrance (Tang Duguang Ting "Qingcheng Mountain": "A Chicheng Mountain in Qingcheng Mountain, a Qingcheng City, a Tianguo Mountain.")The main body is three levels horizontally and vertically divided into two layers. The roof tiles are small, and the front, the slant, and the sloping ridges are all in the form of spaces. It looks natural and comfortable. Only the red-green kisses on the ridge of the pavilion count as the ridge "beast", and the rest are statues of flowers and celestial beings .The elements of the Eight Immortals crossing the sea are used repeatedly, including He Xiangu's lotus (Dark Eight Immortals) and the pros and cons of the Eight Immortals (Ming Eight Immortals). The traditional elephant stands at the corner of the wing and is also a romantic and rich accumulation. Compared with the Jianfugong Mountain Gate, the Chicheng Pavilion is more civil and more flexible. It is in line with its existence as a signpost on the road to the mountain. Unlike other parts of China, this mountain gate uses Sichuan's unique decorative method to distribute character sculptures and small beasts throughout the roof. The immortal monks in the Taoist story stand on the ground and let people quickly enter the cultural atmosphere of Taoism. In fact, this is not only to show the religious background of the building, but to cover up the end of the chain used to cover the fixed ridge.

\subsection{Hall decoration}

The decoration of the main hall is mainly undertaken by the window carvings. In the palaces of Qingcheng Mountain, the inner windows are mostly wooden partitions. The partition is a distinctive wooden construction in traditional architecture. It can be used as both a door and a window, and it can also be used as a dividing wall. Because it is a non-load bearing member that is independent of the building beam and located on the main facade of the building. Therefore, the craftsmen are doing everything they can to decorate them, such as: The story pattern of the first hall of Jianfu Palace tells the story of the immortals. The four corners are bat patterns. In the traditional Chinese decorative art, the shape of the bat is a symbol of happiness. The homonym of "bat" and "Fu" combines the advent of bats into the meaning of "being a blessing", expecting happiness to fall like a bat. The "井" pattern of the Zhangren Temple corresponds to the first place in the south of the twenty-eight stars in the Sky dome. The "井" pattern is used as the decoration of the door and window pattern, which corresponds to the building and the well-being. It is connotation of the stars in the sky, and the pattern has a symbol of fire prevention, which means lucky The word "亚" is related to the sacrifice of the ancients. In ancient times, the skull shape had a very high architectural image. The sub-character in the heart pattern of the pane originated from the worship of the sun by the distant ancestors, which is extremely noble. How can the owner's identity in such a noble pattern be low? Lantern pattern, the connotation of the light here makes the evil spirits difficult to get close. It means that the future of the road is as bright as the lanterns, and the cause will surely succeed. ${ }^{[2]}$ The multi-layered heart of the panes has an openwork effect, which symbolizes the inexhaustible source of food and has no worries. The diamond pattern in the window, with a combination of single and integral. Water chestnut, as a food, is a symbol of nature's harvest. In addition, this pattern is also a mesh shape of the original ancestor fishing. is a symbol of wealth. ${ }^{[3]}$ 


\subsection{Courtyard decoration}

The most attractive aspect of the decoration in the courtyard is the railing.

The railing, as a safety facility in the building, serves the dual function of protection and guidance. As the focus of human vision, the baluster capital is often beautifully carved. The baluster capital of Cloud pattern is the most common style in the baluster capital of the Qingcheng Mountain. It is set on the road with lower level requirements and expresses blessings. The Lotus baluster capital appears in the highest building in the building community - Laojun Pavilion. Lotus was originally one of the symbols of Buddhism. After cultural integration, the cultures of the two religions are constantly combined in the architectural art of Qingcheng Mountain. On both sides of the road, there are twelve zodiac's the baluster capital, two pairs of opposite, six reincarnations. Wisdom, hard work, courage, caution, fierceness, flexibility, unity and harmony are all incorporated into the sculpture. The other part is carved into the image of Taoism and Buddhism. For example, there are Liu Haixian people with awkwardness, Buddha, smiling faces Buddha, Guanyin Bodhisattva.......At the entrance of Jianfu Palace, the characters of the baluster capital are very vivid. Unfortunately, some parts are already broken. Among them, children play and embrace the carp are expressing blessings. There is also a pumpkin stigma. In the Journey to the West, Emperor Taizong told the Ten Kings that he could return with the fruits. The Ten Kings said that there was only a pumpkin in this place, and Tang Taizong sent pumpkins. These sculptures show that people's beautiful expectations of secular life deeply influence the cultural core of Taoism and are the intuitive embodiment of Taoism secularization.

\subsection{Other decorations}

There are also rich paintings in the Qingcheng Mountain Road View Group for the beams and walls, and the carvings are used for the bird's legs and the calves. They all use the image of Taoist gods such as the Eight Immortals. These decorations complete the Taoist culture in the Taoist landscape in terms of spatial layout, allowing the believers and tourists to feel the Taoist elements most directly. However, for various reasons, the past murals and finches have not been well preserved. We can only see the newly painted mythological ghosts and the new flying man engraving on the wall of the palace building. Fortunately, we can still feel the prosperous time of the Taoist architectural decoration of Qingcheng Mountain from the historical records.

\section{Conclusion}

As the emergence of the Taoist ancestor Zhang Daoling, the famous "Five-Day Heaven", the background and culture of the Qingcheng Mountain Taoist architecture are very representative. As a national 5A-level tourist attraction, it also faces the problem of cultural heritage and tourism integration while enjoying the rich economic returns brought by cultural heritage. The existing Taoist decorative arts gradually tend to cater to the secular direction, in which the religious spirit gradually weakens. Is it good or bad? Studying the existing buildings and understanding the history of Taoist decoration, the true meaning is actually inheriting our traditional culture and protecting our spiritual context.

\section{References}

[1] Linfan Zhang. 2013. A study on the relationship between Buddhism and Taoism in the Han, Wei, Southern and Northern dynasties. China. No. 6(2013), p.45-46.

[2] Zhuo Chen. Study on the pattern of window in Suzhou Gardens (Master, Hebei University of Science and Technology, 
China, 2015).

[3] Information on: https://www.sohu.com/a/192198772_617491. 